\title{
The Moderator Role of Individual Goal Clarity in the Relationships between Career Goal Discrepancies and Distresses
}

\author{
Dian Ratna Sawitri \\ Faculty of Psychology and Center for Career and Capacity Development Studies (CAREERS) \\ Diponegoro University, Central Java, Indonesia \\ dian.r.sawitri@gmail.com \\ Mirwan Surya Perdhana \\ Faculty of Economics and Business and \\ Center for Career and Capacity Development Studies (CAREERS) \\ Central Java, Indonesia \\ mirwan@live.undip.ac.id \\ Bambang Suryadi \\ Faculty of Psychology, Universitas Islam Negeri (UIN) Syarif Hidayatullah \\ Jakartalndonesia \\ bambang.suryadi@uinjkt.ac.id
}

\begin{abstract}
Discrepancies between individuals and their parents regarding career goals often present as inevitable conditions that have the potentials to influence individual career distress and also parental career distress from the perspective of the individual. This study aimed to investigate the moderating role of individual goal clarity on the relationships between individual-parent career goal discrepancies and individual and parental career distresses. We collected data from 205 freshmen of an university in Semarang, Indonesia, $M$ age $=18.35$ years, SD age $=.64,68.3 \%$ female. We used the Individual-Parent Career Goal Discrepancies Scale $(\alpha=.93)$, Goal Clarity Scale $(\alpha=.84)$, Career Distress Scale $(\alpha=.87)$, and Parental Career Distress Scale $(\alpha=.8 \mathrm{I})$. Hierarchical regression analyses demonstrated that as discrepancies increased, individual and parental career distress increased for high goal clarity and low goal clarity groups. However, those variables increased more markedly for the low goal clarity group. Our results highlight the important role of individual goal clarity in the consequences of individualparent career goal discrepancies on young people's and parental distresses. Recommendations for students, parents, and practitioners are discussed.
\end{abstract}

Keywords: career, discrepancies, distress, goal clarity, parents

Received II October 2019/Accepted 25 November 2019 @ JEHCP All rights reserved 


\section{Introduction}

Individual career distress is a normal consequence of negative career situations experienced by an individual, such as career decision-making difficulties, poor career preparation, and facing careerrelated barriers (Creed, Hood, Praskova, \& Makransky, 2016). As one of the typical causes of stress in educational settings, up to $25 \%$ of students attended campus counseling services seeking vocational-related help (Benton, Robertson, Tseng, Newton, \& Benton, 2003). Individual career distress is specific to the career domain and refers to a variety of overwhelming negative feelings, which include helplessness, depression, ambiguity, stress, fear, guilt, and hopelessness(Larson et al., 1994).

Parent career distress is an individual's perception regarding the level of their parent's careerrelated distress. Efforts to identify and understand the dynamics that lead to career distress is crucial, as this provides encouragement to young people to manage their career aspirations and planning, and it opens the opportunities for developing programs that can help those who experience career uncertainty (Lent \& Hackett, 1994).

The previous study showed that career preparatory activities of exploration and planning were associated with perceived employability and stress regarding career matters (Praskova, Creed, Hood, 2015). Previous research also demonstrated that career goal-performance discrepancy was correlated significantly directly and indirectly with interpersonal rejection sensitivity and individual career distress, and it was indirectly associated with proactive personality and employability (Creed, Hood, \& Hu, 2017).

Career goals are an individuals' expressed career-related goals towards leadership positions, motivation to train and to help and handle others, and interest in continuing schooling (O'Brien, 1996). Career goal setting is important to study during adolescence because it is a crucial development task in the process of career preparation and the individual's vocational identity development(Erikson, 1968). Older adolescents are expected to become increasingly adjust their goals and modify their career goals realistically over time (Armstrong \& Crombie, 2000). 
Individual-parent career goal discrepancies are often present as an inevitable situation that happens when individual perceived disparities between parent-set career goals and their own, self-set career goals, which incorporated discrepancies between the individuals' ability, choice, and enthusiasm and the career goals that their parents had for them (Sawitri, Creed, \& Perdhana, 2019). Previous studies demonstrated that discrepancies between individual-set and parent-set career goals were associated with higher career distress (Sawitri et al., 2019). However, the effect of discrepancies on parent career distress from the perspective of an individual has not been assessed. Additionally, the condition under which discrepancies happen will be more likely to increase individual, and parent career distresses, therefore warrant further examination.

The central premise of Goal Setting Theory (GST) is that motivating young people to chase clear and challenging goals leads to more performance benefits than asking them to pursue unclear and easy goals or to do what they can do best (Locke et al. 1990). Literature in management and applied psychology define goal clarity as "the extent to which the outcome goals and objectives of the job are clearly stated and well defined" (Sawyer 1992). Individual goal clarity has been investigated in the organizational setting. However, it has not been assessed in the area of young people's career development as a moderator.

Individuals with a clearer career goal and more well-established career identity should be able to manage these challenges better and, benefit from higher well-being and lower psychological distress (Porfeli, Lee, \& Vondracek, 20I3), as they have better plans and strategies to direct themselves and to solve career-related problems. Previous studies with emerging adults have shown positive relationships between career-related identity and satisfaction with life (Hirschi, 20II; Hirschi \& Herrmann,2012) and negative correlations with career-related distress and negative career thoughts (Strauser, Lustig, Cogdal, \& Uruk, 2006).

Therefore, we hypothesized that: (HI) Individual goal clarity would moderate the relationship between individual-parent career goal discrepancies and individual career distress; $(\mathrm{H} 2)$ Individual goal clarity would moderate the association between individual-parent career goal discrepancies and parent career-related distress. 


\section{METHOD}

\section{Participants}

We gained data from 205first year undergraduate students (semester $2, M_{\text {age }}=18.35$ years, $68.3 \%$ female, Mean GPA = 3.32) who were recruited from a state university, in Semarang, Indonesia. Participants were obtained using convenience sampling and were drawn from Psychology (43.9\%) and Economics and Business (56.1\%) disciplines. Ethical clearance was obtained from the authors' university.

\section{Data Collection Methods}

Data were collected using a modified 6-point Likert like scale, from $(1=$ strongly disagree to 6 =strongly agree). Higher scores denote higher levels of each construct.

\section{Materials}

Discrepancies between Individual and Parent-Set Career Goals Scale

Discrepancies between individual and parent-set career goals were assessed using the 15-items Individual-Parent Career Goal Discrepancies Scale (Sawitri et al., 2019). Sample item: "I do not think I can meet the requirements for the career my parents want for me."Previous research has reported internal reliability of .95 , and evidence for construct validity was shown by finding expected associations with measures of congruence with parents regarding career issues and career distress (Sawitri et al., 2019). Cronbach's alpha for this study is .93.

\section{Individual Career Distress Scale}

Individual career distress was measured using the Career Distress Scale (Creed et al., 20I6), which consisted of 9 items. It measures levels of subjective distress regarding career decision-making and career goal-setting activities. A sample of items is"I often feel down or depressed about selecting a career," "I think that I should make a career decision as soon as possible, but I cannot, and this makes me anxious," "I feel stress or pressure to select a satisfying career." The previous study has reported high internal reliability (.90), and support for validity by demonstrating expected correlations with negative affect and also positive affect (Creed et al., 20I6). Cronbach's alpha for this study is .87. 
Parent Career Distress Scale

Parent career distress was measured using the modified version of the Career Distress Scale, consisting of 9 items (Creed et al., 2016). We modified items, such as, “I don't have the special talents to follow my first career choice" to "My parents think that I don't have the special talents to commit to their career preference"; "I often feel that my life lacks many purposes" to "My parents feel that I often feel that my life lacks many purposes"; "I feel stress or pressure to select a satisfying career" to "My parents think that I feel stress or pressure to select a satisfying career"). Cronbach's alpha for this study is .8I.

\section{Goal Clarity Scale}

We created the 6-item Goal Clarity Scale, specifically for this study, to assess the clarity of the individual's own career goal. Sample items are: “I am clear about the career I want”; “I am unsure about the career I really want to achieve (R)"; "I am still confused about the careers I want to get (R)."Cronbach's alpha for this study is .84.

\section{Translation Procedures}

Scale items were translated from English to Bahasa Indonesia using the forward and backward translation technique(Brislin, 1986): (a) two bilingual speakers translated the items into Bahasa Indonesia, (b) two monolingual speakers examined whether the translation versions were easy to understand, (c) two bilingual speakers blindly translated the items in Bahasa Indonesia into English, (d) the back-translation was match up to the original version to check semantic accuracies, and errors were adjusted, and (e) three Indonesian students assessed whether the final items were easy to read.

\section{Data Collection Procedure}

The study was conducted with permission from the ethics committee in the authors' university. Written permission was obtained from the participating university departments and all students in the study. The survey booklets which contained the scales and demographic questions were administered to students in class time at the campus. 


\section{Data Analysis}

We used hierarchical regression analyses to assess whether individual goal clarity moderated the relationship between discrepancies between individuals and their parents regarding career goals and individual career distress and parent career distress. To the hypothesis I, discrepancies were involved at Step I, individual goal clarity at Step 2, and then the interaction term (i.e., discrepancies $x$ individual goal clarity), as suggested by Jose (2013) at Step 3. To the hypothesis 2 , we did the same thing.

\section{Results}

Table I displays summary data, which includes means and standard deviations of each variable, and bivariate correlations among variables.

Table I

Summary Data and Bivariate Correlations; $N=205$

\begin{tabular}{lcccccc}
\hline \multicolumn{1}{c}{ Variable } & $M$ & SD & $\mathrm{I}$ & 2 & 3 & 4 \\
\hline I. Discrepancies & 36.05 & 13.62 & - & $.43^{* * *}$ & $.54^{* * *}$ & $-.23^{* * *}$ \\
2. Individual career distress & 24.49 & 7.98 & & - & $.53^{* * *}$ & $-.58^{* * * *}$ \\
3. Parent career distress & 24.42 & 7.07 & & & - & $-.29 * * *$ \\
4. Individual goal clarity & 25.74 & 4.82 & & & & - \\
\hline
\end{tabular}

We conducted hierarchical regression analyses to determine the moderated effects. Discrepancies were entered at Step I and accounted for $18.3 \%$ of the variance in individual career distress, $F(I$, $203)=45.58, p<.00 \mathrm{I}$. Individual goal clarity at Step 2 accounted for an additional 24.3\%, F (I, 202) $=85.70, p<.00 \mathrm{I}$. At Step 3, the interaction term was significant, $F(\mathrm{I}, 20 \mathrm{I})=10.0 \mathrm{I}, p=.0 \mathrm{I}$, and $44.6 \%$ of the variance in individual career distress was accounted for. See Table 2. 
Table 2

Results of hierarchical regression analysis $(N=205)$

\begin{tabular}{|c|c|c|c|c|}
\hline \multirow[t]{2}{*}{ Variables } & \multicolumn{4}{|c|}{ Individual career distress } \\
\hline & $\mathrm{R}^{2}$ & B & SE (B) & $\beta$ \\
\hline Step I & & & & \\
\hline Discrepancies & $.18 * * *$ & .66 & .18 & 1.126 \\
\hline Step 2 & & & & \\
\hline $\begin{array}{l}\text { Individual goal clarity } \\
\text { Step } 3\end{array}$ & $.24 * * *$ & -.22 & .25 & -.86 \\
\hline $\begin{array}{l}\text { Discrepancies } \mathrm{x} \text { individual goal } \\
\text { clarity }\end{array}$ & $.02 * *$ & -.02 & .01 & -.83 \\
\hline
\end{tabular}

Results demonstrated that discrepancies were associated negatively with individual career distress. However, the association was stronger for those who have low individual goal clarity. See Figure I.

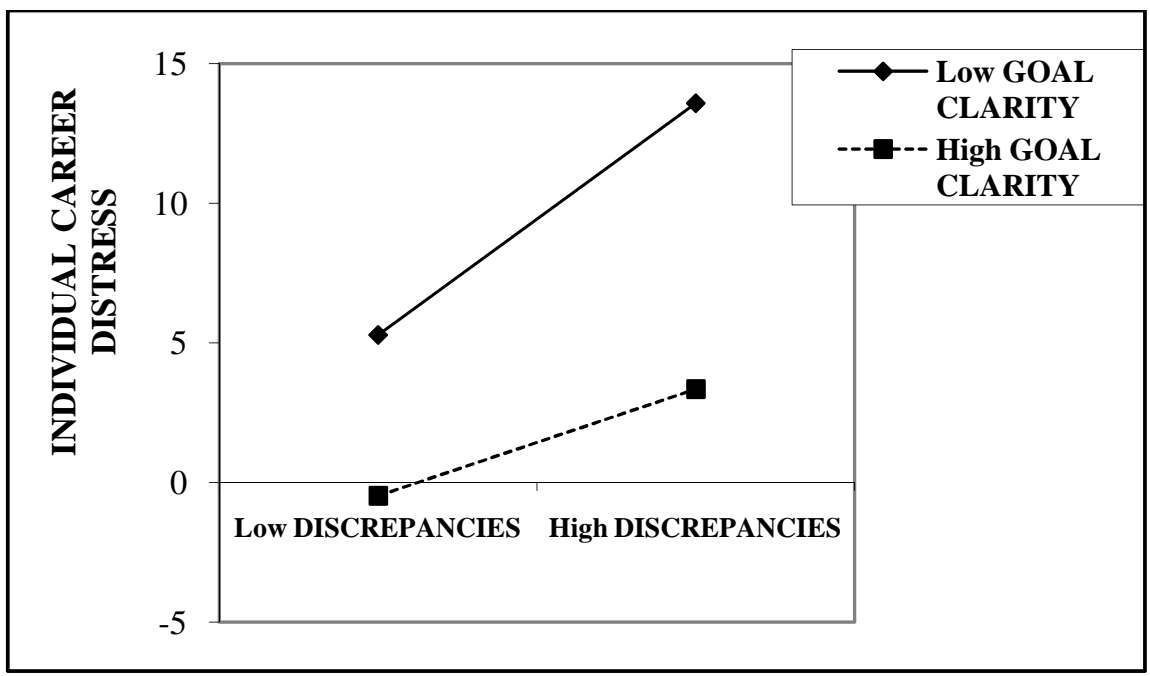

Figure I. The moderator role of individual goal clarity in the association between individualparent career goal discrepancies and individual career distress

To test hypothesis 2 , discrepancies was entered at Step I, and accounted for $29.6 \%$ of the variance in parent career distress, $F(I, 203)=85.37, p<.00 \mathrm{I}$. Individual goal clarity at Step 2 accounted for an additional 3\%, $F(I, 202)=85.70, p<.00 I$. At Step 3, the interaction term was significant, $F(I$, $201)=10.01, p=.05$, and $34.2 \%$ of the variance in parent career distress was accounted for. See Table 3. 
Table 3

Results of hierarchical regression analysis $(N=205)$

\begin{tabular}{lcccc}
\hline \multicolumn{1}{c}{ Variables } & \multicolumn{4}{c}{ Parent career distress } \\
\hline $\begin{array}{l}\text { Step I } \\
\text { Discrepancies }\end{array}$ & $\mathrm{R}^{2}$ & $\mathrm{~B}$ & $\mathrm{SE}(\mathrm{B})$ & $\beta$ \\
$\begin{array}{l}\text { Step 2 } \\
\text { Individual goal clarity }\end{array}$ & $.29 * * *$ & .65 & .18 & 1.246 \\
$\begin{array}{l}\text { Step 3 } \\
\text { Discrepancies x individual goal } \\
\text { clarity }\end{array}$ & $.03^{* *}$ & -.24 & .24 & -.17 \\
\hline
\end{tabular}

Results showed that discrepancies were associated negatively with parent career distress. However, the association was stronger for those who have low individual goal clarity. See Table 3.

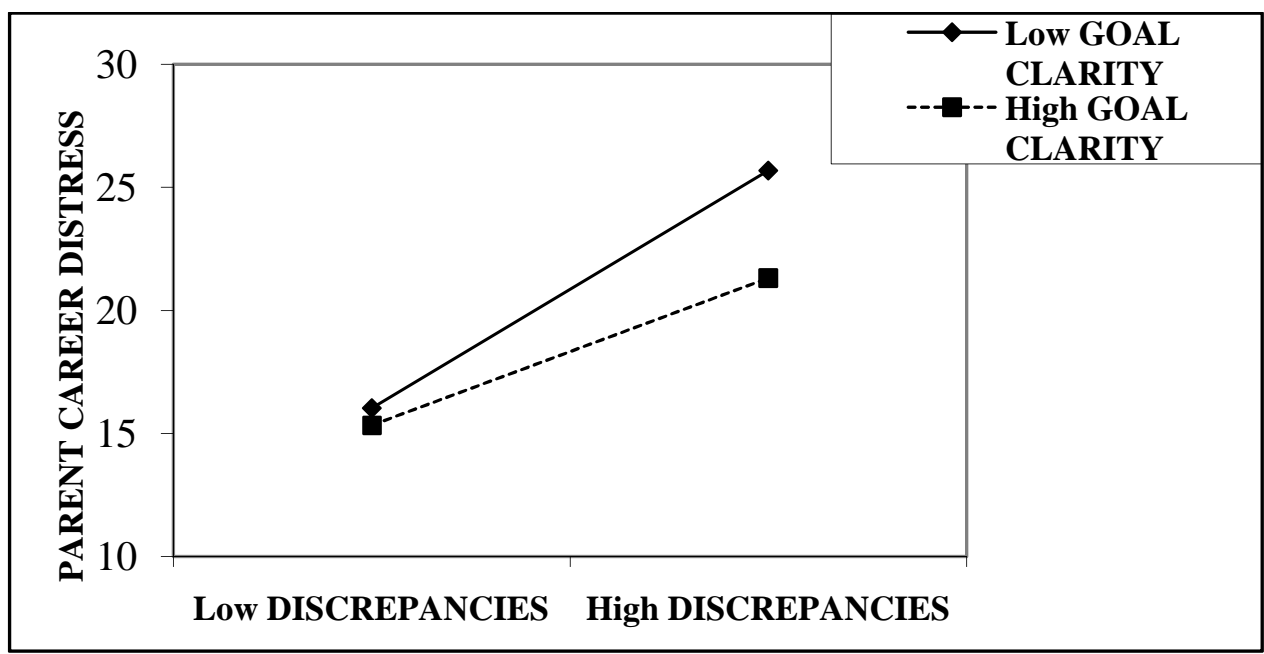

Figure 2. The moderator role of individual goal clarity in the correlation between individual-parent career goal discrepancies and individual career distress

\section{Discussion}

The study was aimed to examine the moderator role of individual goal clarity in the association between individual-parent career goal discrepancies and individual career distress, and also in the association between individual career goal discrepancies and parent career distress. We proposed 
that individual goal clarity served as a moderator in the relationships between discrepancies and both individual and parent career distresses.

We found a significant positive relationship between discrepancies and individual career distress and found that the relationship was stronger when individual goal clarity was lower. This suggests that those who have higher discrepancies are more likely to feel higher individual career distress, especially for those who have low individual goal clarity. We also found a significant positive relationship between discrepancies and parent career distress and found that the relationship was stronger when individual goal clarity was lower, suggesting that those who have higher discrepancies are more likely to feel higher parent career distress, especially for those who have low individual goal clarity. These results are consistent with the goal-setting theory (Locke et al., 1990), that clear goals lead to better performance.

This result confirms the previous study, which demonstrated that career compromise was correlated positively with career distress and negatively with perceived employment need. Individuals compromise on their career goals when they face real or perceived barriers to achieving them, which can be external such as family expectations that differ from an individual's goals or internal such as lack of career self-efficacy (Creed \& Gagliardi, 20I5). This finding is also in line with Wang and Heppner's (2002) study, which demonstrated that individuals who were perceiving themselves as failing to live up to parental expectations rather than merely perceiving parental expectations were more likely to report psychological distress.

Our findings have several implications. First, interventions aimed at assisting students to reduce individual and parent career distress might include a focus on reducing discrepancies between individual-set and parent-set career goals and increasing individual goal clarity, as lower discrepancies cannot stand alone. This intervention would allow students with an unclear individual career goal to check their aspirations and make sure that they commit to achieving certain goals. Second, discrepancies between individual-set and parent-set career goals should be reduced by conducting an effort to fine-tune their aspirations and parents' expectations. 
As our study was conducted using a sample of students from one university in Semarang, Indonesia, the conclusions of this study need to be tested on other student populations. Additionally, the data were collected at one point in time. Therefore, future studies could focus on testing across time associations among variables to get stronger causal conclusions. Last, although we discovered a significant interaction effect, the variance explained was very modest. These findings suggest that contextual variables might play a role in moderating the relationship, and therefore, need to be investigated.

\section{Conclusion}

Results from our study demonstrated that as discrepancies increased, individual and parental career distress increased for high and low goal clarity groups. However, they improved more markedly for the low goal clarity group. These results highlight the important role of individual goal clarity in the consequences of individual-parent career goal discrepancies on young people's and parental careerrelated distresses.

\section{References}

Armstrong, P. I., \& Crombie, G. (2000). Compromises in adolescents' occupational aspirations and expectations from grades 8 to 10. Journal of Vocational Behavior, 56, 82-98. DOI:10.1006/jvbe.1999.1709

Erikson, E. H. (1968). Identity: Youth and crisis. New York, NY: Norton.

Brislin, R. W. (1986). The wording and translation of research instruments. In W. J. Lonner \& J. W. Berry (Eds.). Field methods in cross-cultural research (pp. 137-164). London, UK: Sage Publications, Inc.

Creed, P. A., \& Gagliardi, E-R. (2015). Career compromise, career distress, and perceptions of employability: The moderating roles of social capital and core self-evaluations. Journal of Career Assessment, 23, 20 - 34. DOI:I0.I I77/I0690727/4523082

Creed, P. A., Hood., M. H., \& Hu, S. (20I7). Personal orientation as an antecedent to career stress and employability confidence: The intervening roles of career goal-performance discrepancy and career goal importance. Journal of Vocational Behavior, $99,79-92$. DOI:10.1016/j.jvb.2016.12.007 
Creed, P. A., Hood, M. H., Praskova, A., \& Makransky, G. (2016). The Career Distress Scale. Using Rasch measurement theory to evaluate a brief measure of career distress. Journal of Career Assessment, 24, 732-746. DOI:10.1I77/10690727/56/6126

Hirschi, A. (20II). Vocational identity as a mediator of the relationship between core selfevaluations and life and job satisfaction. Applied Psychology An InternationalReview, 60, 622-644. DOI: 10.1 III/j.1464-0597.20II.00450.x

Hirschi, A., \& Herrmann, A. (20I2). Vocational identity achievement as a mediator of the presence of calling and life satisfaction. Journal of Career Assessment, 20, 309-32I. DOI: 10.1 I77/10690727/1436/58

Jose, P. E. (20I3). Doing statistical mediation and moderation. New York, NY: The Guildford Press.

Lent, R. W., \& Hackett, G. (1994). Sociocognitive mechanisms of personal agency in career development. In M. L. Savickas, \& R. W. Lent (Eds.), Convergence in career development theories: Implications for science and practice (pp. 77-10I). Palo Alto, CA: CPP Books.

Locke, E. A., Latham, G. P., Smith, K. J., Wood, R. E., \& Bandura, A. (1990). A theory of goal setting \& task performance, vol. 2 I. Englewood Cliffs, NJ: Prentice-Hall.

O'Brien, K. M. (1996). The influence of psychological separation and parental attachment on the career development of adolescent women. Journal of Vocational Behavior, 48, 257-274. DOI:10.1006/jvbe.1996.0024

Porfeli, E.J., Lee, B., \& Vondracek, F.W. (20I3). Identity development and careers in adolescents and emerging adults. InW.B. Walsh, M.L. Savickas, \& P. Hartung (Eds.), Handbook of vocational psychology (pp. 133-154). New York, NY: Routledge Press.

Praskova, A., Creed, P. A., \& Hood. (2015). Career identity and complex mediation relationships between career preparatory actions and career progress markers. Journal of Vocational Behavior, 87, I45 - I53. DOI:I0.1016/j.jvb.2015.0I.00I

Sawitri, D. R., Creed, P. A., \& Perdhana, M. S. (2019). The discrepancies between individual-set and parent-set career goals scale: Development and initial validation. Accepted for publication in the Journal of Career Development.

Sawyer, J. E. (1992). Goal and process clarity: Specification of multiple constructs of role ambiguity and a structural equation model of their antecedents and consequences. Journal of Applied Psychology, 77, 130-42.

Strauser, D.R., Lustig, D.C., Cogdal, P.A., \& Uruk, A.C. (2006). Trauma symptoms: Relationship with career thoughts, vocational identity, and developmental work personality. The Career Development Quarterly, 54, 346-360. DOI:10.1002/j.2161-0045.2006.tb00199.x.

Wang, L.-F., \& Heppner, P. P. (2002). Assessing the impact of parental expectations and psychological distress on Taiwanese college students. The Counseling Psychologist, 30, 582-608. DOI:10.1177/00100002030004006. 